\title{
GODS HAND IN DIE NATUUR
}

Kan ons van so iets spreek? Daaroor bestaan daar seker geen verskil nie. Die Bybel is vol daarvan van Genesis tot Openbaring. God is Skepper.

'n Ander vraag is of ons God ook kan ken uit wat daar in die natuur gebeur? Verloop alles nie maar volgens ewige natuurwette waaraan tog niks verander kan word nie?

Ons bely egter dat die Here nie net in die hart van die mens gelê het wat ons noem die ,saad van die religie" nie (semen religionis), maar dat ons Hom ook ken deur die skepping, onderhouding en regering van die hele wêreld, aangesien dit voor ons oë is soos ' $n$ mooi boek waarin alle skepsels, groot en klein, die letters is wat ons die onsigbare dinge van God duidelik laat sien, nl. sy ewige krag en Goddelikheid...; dinge wat almal genoegsaam is om die mense te oortuig en hulle alle verontskuldiging te ontneem (Art. 2 Ned. Gel. Bel.).

Calvyn sê dat God Homself in die hele bouwerk van die wêreld so geopenbaar het, en Homself elke dag daarin so openlik aanbied dat die mense hulle oë nie kan oopmaak nie, of hulle word gedwing om Hom te sien. Sy Wese is wel onbegryplik..., maar in elkeen van sy werke afsonderlik het Hy onbetwyfelbare kentekens van sy heerlikheid ingegrif, wat so duidelik is en in die oog val dat elke voorwendsel van onwetendheid weggeneem is, al is die mens ook nog so onkundig en dom.

'n Bietjie verder aan sê hy "daar is geen enkele deeltjie van die wêreld waarin ons nie enige vonkies van sy heerlikheid kan sien glinster nie. Ons kan hierdie uitgestrekte en pragtige kunswerk nie aanskou, sonder om van alle kante deur die onmeetlike krag van sy skittering oorstelp te word nie" (Inst. I, V, 1).

Ook die mens se liggaam is so vernuftig saamgestel dat dit aan ons 'n bewonderenswaardige Maker openbaar. Daarom het sommige wysgere die mens... 'n mikrokosmos genoem .. omdat hy ' $n$ buitengewone toonbeeld is van die mag, goedheid en wysheid van God en voldoende wonders in hom bevat om ons gees besig te hou. Hy verwys dan na Hand. $17: 27$. Ons hoef nie buite onsself te gaan om God te vind nie. So het Calvyn die skeppingswerk gesien. Van alle kante word hy oorstelp deur die onbeskryflike prag van die skittering van 
Gods heerlikheid. So ook die Vlaamse digter Guido Gezelle, om nie meer te noem nie.

En nou het hy hierdie woorde wel in die eerste plek gebesig van die skeppingsgebou as sodanig, maar dit geld net so wel van die onderhouding en besturing van daardie gebou. Ons mag skepping en onderhouding van die skepping nie só onderskei dat ons hulle naderhand hermeties van mekaar afgesluit het nie. Die Bybel doen dit nie (vgl. bv. Ps. 104). Calvyn doen dit ook nie. Ons ken God nie net uit die skepping van die wêreld nie, maar ook uit die voortdurende besturing daarvan (I, V). Een sitaat sal voldoende wees. In verband met dié dinge wat nie volgens die gewone loop van die natuur geskied nie, sê hy: „In die bestuur van die menslike gemeenskap reël God sy voorsienigheid só, dat Hy ... met duidelike en daelikse kentekens aan die vromes sy goedertierenheid, aan die goddeloses sy gestrengheid betoon" (I, V, 7). Ons moet skepping en onderhouding dus onderskei, maar altyd in gedagte hou dat dit dieselfde God is wat onderhou nadat $\mathrm{Hy}$ geskep het, anders verval ons in die arms van die Deïsme. Dan gebeur die dinge „maar so by toeval, en glo ons nie meer nie dat lower en gras, reën en droogte, vrugbare en onvrugbare jare, spys en drank, gesondheid en krankheid, rykdom en armoede, en alle dinge nie by toeval nie; maar uit Gods vaderlike hand ons toekom" (Heid. Kateg., vraag 27). Ons het dan 'n wêreld vol afgode maar sonder God. Dis onweerlegbaar. Wie Gods hand nie sien in die natuurgebeure, begryp nie wat dit beteken dat God Skepper is nie. Al vat hy dit ook met sy verstand en bely hy dit met sy tong, sê Calvyn.

\section{Die voorsienigheid van God}

Aangaande die voorsienigheid van God waarvan ons onderwerp "Gods hand in die natuur" maar 'n onderdeel is, bely ons ,dat die goeie God, nadat Hy alle dinge geskape het, hulle nie laat vaar het of aan die toeval of die geluk oorgegee het nie, maar hulle na sy heilige wil so bestuur en regeer dat in hierdie wêreld niks sonder sy beskikking gebeur nie, alhoewel God geensins die Bewerker is en ook nie skuld dra van die sonde wat gedoen word nie...

En met betrekking tot die dinge wat $\mathrm{Hy}$ doen bo die begrip van die menslike verstand, wil ons nie 'n nuuskierige 
ondersoek instel wat ons begrip nie kan bevat nie; maar ons aanbid met alle ootmoedigheid en eerbied die regverdige oordele van God, wat vir ons verborge is, en ons stel ons daarmee tevrede dat ons leerlinge van Christus is om alleen te leer ken wat Hy ons aanwys in sy Woord, sonder om hierdie perke te oortree..." (Art. 13, Ned. Gel. Bel.).

Die Heidelbergse Kategismus omskryf dit as ,die almagtige en alomteenwoordige krag van God, waardeur Hy hemel en aarde en al die skepsels as met sy hand nog onderhou en so regeer dat lower en gras, reën en droogte, vrugbare en onvrugbare jare, spys en drank, gesondheid en krankheid, rykdom en armoede en alle dinge nie by toeval nie, maar uit sy vaderlike hand ons toekom" (Sond. $\mathrm{X}$ ). Die twee omskrywinge dek nie net die hoofsaak nie, maar gee ook uitnemend weer die gees waarin die vaders hierdie leerstuk, soos trouens al die ander dogmas, benader het: Vrae sal daar altyd gestel kan word wat geen mens kan beantwoord nie. Daarom staan ook vir ons voorop dat ons met alle ootmoedigheid en nederigheid die oordele van God aanbid, en ons daarmee tevrede stel dat ons leerlinge van Christus is om alleen te leer ken wat Hy ons aanwys in sy Woord.

Calvyn sê kort en bondig dat voorsienigheid nie beteken dat God werkeloos uit die hemel aanskou wat daar op aarde gebeur nie, maar dat $\mathrm{Hy}$, om dit so uit te druk, die roer vashou, en alle gebeurtenisse bestuur. Dit beteken dus werksaamheid (I, XVI, 4).

Ons kan dus met reg spreek van Gods hand in die natuur. Wie dit betwyfel kan maar net die tekste naslaan wat die Kategismus opgee by vraag 27.

\section{Enkele afleidings}

1. Uit bostaande is dit duidelik dat as ons spreek van die hand van God in die natuur, ons daarmee nie bedoel die werkinge van 'n natuurwet wat God in die begin in die natuur gelê het en wat nou maar blindweg, meganies funksioneer nie. Nee ons bedoel elke woord letterlik net soos dit daar staan. God onderhou en bestuur van oomblik tot oomlik hierdie grote skepping tot in die fynste besonderhede toe. Ons duisel as ons maar net probeer om te dink aan die miljoene sterre wat God elkeen by sy naam noem (Jes. $40: 26$ ); aan 
die miljoene en nogmaals miljoene wesens, redelik en onredelik, wie se behoeftes afsonderlik vervul moet word. As daar net een deeltjie van die skepping is wat God nie bestuur nie, hoe gering ook al, dan is Hy nie meer God nie. In verband met wat ons lees in Jes. $10: 13$ en 2 Kon. 20 : 11 maak Calvyn die opmerking dat God deur hierdie wonders betuig dat die son nie elke dag deur 'n blinde aandrywing van die natuur opgaan en ondergaan nie, maar dat $\mathrm{Hy}$ sy loop bestuur om die herinnering van sy vaderlike guns jeens ons te vernuwe. Diegene wat van Gods voorsienigheid 'n ewige natuurwet maak, beroof God van sy eer en hulself van 'n nuttige leerstuk. Want daar is seker niks ellendiger nie as die mens wat die prooi is van die grille van 'n blinde natuurwet. Daar is onder ons gelowiges geen verskil van opvatting oor die vraag of Gods hand ook gesien kan word in die daelikse onderhouding en regering van die groot skepping nie. Maar lees ons die Godspraak op dieselfde manier, en verstaan ons almal wat God dan so deur die natuurgang spreek op dieselfde manier? Ons neem bv. die saak van droogtes wat gedurig voorkom. Die gangbare opvatting is dat God ons met droogtes besoek omdat die volk van die Here afgewyk het. Droogte is dus 'n kastyding van die Here wat oproep tot verootmoediging en bekering tot God. Daarom bepaal die drie Afrikaanse kerke biddae in oorleg met mekaar.

Maar daar is ook mense wat anders oor die saak dink. Hulle merk op dat net sekere dele van ons land aan droogtes onderhewig is. Nou vra hulle of droogte dan nie die normale beskikking van God vir ons wêrelddeel is en gaan ons dan nie te ver as ons in die droogtes die oordele van die Here sien nie? Die mense het dan ook beswaar daarteen om biddae te hou met die oog op die droogte-toestande. Hulle vra of dit dan nie inhou dat ons nie God se beskikking en natuurordening vir ons land aanvaar nie. Moet ons nie met bosaanplanting en waterbesparing die heftigheid van die droogte bekamp of probeer bekamp, soos gedoen is met die sprinkane wat vroeër ook as plae van die Here beskou is, maar wat deur wetenskaplike metodes nou onder beheer of redelik onder beheer gebring is nie?

Met mense wat gemoedsbesware het moet versigtig gehandel word. Dit gaan met die mense ook oor God en nie 
oor die mens nie. Hulle wil God ook die eer gee wat Hom toekom, net soos die ander wat die biddae waarneem. Tog meen ek dat hulle redenering nie suiwer is nie. Dit gaan nie daaroor óf ons die droogtes moet bestry met al die middels wat die Here ons ter hand stel nie en óf ons net moet bid nie. Hier geld seker ook die bevel: bid en werk. Ons moet dus nie óf óf redeneer nie, maar én én. Ons moet die een ding doen en die ander nie nalaat nie. God het vir Adam en Eva rokke van velle gemaak seker ook om hulle te leer dat die mens 'n harde stryd moet voer om sy lewe te beveilig sover dit in sy vermoë is. Ons moet dus met al die middels en verstand wat die Here ons gegee het hard stry ook in sulke tye om te behou wat die Here aan ons sorg toevertrou het, maar altyd onder biddende opsien tot God. En allermins met die bedoeling om die plaag uit te roei of ons nie te skik onder Gods beskikking vir ons wêrelddeel nie. So beskou sal daar op ons biddae seker anders gepreek en gebid word as wat daar gewoonlik gedoen word.

Persoonlik glo ek dat die Here elke land (landstreek) besoek met die plae wat as die normale beskikking vir die land (landstreek) geld. Hy besoek die oostelike dele van ons land nie met die aanhoudende droogte waarmee $\mathrm{Hy}$ die westelike dele besoek nie, want dan sou daar geen lewende wese oorbly nie. Die teenoorgestelde is ook die geval.

Die saak is dus nie net biddae hou en nie voorsorgmaatreëls tref nie, of net voorsorgmaatreëls neem, damme bou, gate boor ens. en nie bid nie, maar dit is sowel die een doen as die ander. Anders moet ons ook nie die dokter inroep in tyc van siekte nie.

2. "Voorsienigheid" sluit ook alle toeval uit. Dit lyk soms asof dinge "toevallig" gebeur. Wat lyk meer na toeval as bv. die saak of die wind waai of nie, of die uitslag van die lot. Tog leer die Skrif dat God spreek en 'n stormwind laat opsteek wat die golwe van die see opsweep (Ps. 107: 25. Vgl. ook Jona $1: 4$ ).

En wat die lot betref leer die Skrif dat elke beslissing daarvan van die HERE kom (Spr. $16: 33$ ). Ons kan hier ook verwys na die wonderbare redding van Dawid (1 Sam. 23 : 26,27 ). Die inval van die Filistyne mag, oppervlakkig beskou, na blote toeval lyk, maar die geloof bely dat God hulle gebruik om Dawid, sy kneg, te red. So ook was die bene van Christus 
breekbaar, omdat $\mathrm{Hy}$ 'n liggaam soos ons gehad het, maar tog is hulle nie gebreek nie, omdat God dit so bepaal het. „As ons toegee dat God die Outeur van die natuurwette is, maar dat alles verder vanself of by toeval verloop... dan sal die wisseling van dag en nag en van winter en somer wel Gods werk wees, insover $\mathrm{Hy}$ aan elkeen...' $n$ vaste wet voorgeskrywe het; as $\mathrm{nl}$. die dae wat op die nagte, die maande wat op die maande, en die jare wat op die jare volg altyd gelykmatig verloop. Maar dit sal dan nie Gods werk wees as die vrugte verbrand word deur oormatige hitte gepaard met droogte of die gesaaides deur ontydige reëns verniel word nie. Die wolke, mooi weer, koue of hitte sou dan ontstaan as gevolg van die ontmoeting van sterre en ander natuurlike oorsake. Maar op dié manier word daar geen plek gelaat vir Gods vaderlike guns of vir sy oordele nie. Dan sou die vrugbaarheid van die een jaar nie 'n besondere weldaad van God wees nie, en die skaarste en honger van die ander een nie 'n vloek en 'n straf nie. In die Wet en die Profete getuig God meermale dat $\mathrm{Hy}$ sy guns bewys as $\mathrm{Hy}$ die aarde met dou en reën bevogtig; en dat dit wel op sy bevel hard word soos yster, die gesaaide deur brand en ander rampe vernietig word, en die akkers deur hael en ander noodweer getref word. As ons dit aanneem is dit seker dat daar geen druppel reën val as God dit nie beveel nie" (Inst. I, XVI, 5).

3. „Voorsienigheid" is ook nie dat God maar net vooruit sien of vooruit weet wat sal gebeur nie. Nee Hy bepaal dit en laat dit gebeur (Jes. 43 : 9-21). As Abraham vir Isak sê dat God vir Homself die lam vir die brandoffer sal voorsien (Gen. $22: 8$ ), dan wil hy hom nie net verseker dat God weet wat sal gebeur nie, maar wil hy die uitslag oorlaat aan die Here wat in moeilike omstandighede uitkoms skenk. As dit nie so was nie, sou God maar net in naam die wêreld regeer, maar nie in der daad nie. Dit is nie die God van die Heilige Skrif nie.

4. Eindelik moet opgemerk word dat die hand van God nie net sigbaar is in die groot omwentelinge wat daar plaasvind nie (oorloë, groot natuurrampe soos aardbewings bv.) en dat dit nie ook net gesien kan word in die wisseling van dag en nag en van die jaargetye nie, maar dat ons dit ook moet sien in wat ons sou kan noem die geringste en nietigste voorvalletjies in die lewe. Die Here Jesus leer ons dat Gods voor- 
sienige bestel algemeen is as Hy sê: „My Vader werk tot nou toe, en Ek werk ook" (Joh. $5: 17$ ), dat God sy son laat opgaan oor slegtes en goeies en laat reën oor regverdiges en onregverdiges (Matth. $5: 45$ ), maar Hy spreek ook van die hare van ons hoof wat almal getel is en van die mossies wat nie op die aarde val sonder die wil van ons hemelse Vader nie (Matth. $10: 29$ ).

Só beskou, sluit dit ook die kwaad in. God laat dit nie maar net toe nie, maar Hy beskik dit en laat dit kom (Jes. $45: 7,1$ Kon. $22: 20-23$, Amos $3: 6$ ). „Hoewel sy mag en goedheid so groot en onbegryplik is dat Hy sy werk baie goed en regverdig beskik en doen, selfs wanneer die duiwels en die goddelose onregverdig handel. $\mathrm{Hy}$ is nie die Bewerker en dra ook nie die skuld van die sonde wat gedoen word nie" (Ned. Gel. Bel. Art. XIII). Vgl. verder Num. 11 : 31, Jona $1: 4,6$, Ps. $107: 25$ e.v. God gee in hopelose omstandighede, plotseling en wonderbaarlik en bo verwagting uitkoms aan ongelukkiges. Daarmee bewys $\mathrm{Hy}$ sy vaderlike goedertierenheid jeens ons. Wie wys is, gee op hierdie dinge ag (Ps. $107: 43$ ).

\section{Die voorsienigheid en die gebruik van middels}

Die belydenis dat God ons in alles regeer, is geen fatalisme nie. Mense maak soms dit daarvan. Dit beteken dan:

(a) Wat die verlede betref, dat die mens nie verantwoordelik is vir sy dade nie, want hy het dan net Gods wil uitgevoer. Op dié wyse word van sondige dade deugde gemaak. Sondige vroom word dan in Gods wil berus. Of 'n beroep gedoen op sy voorsienigheid.

(b) Eweso word dan wat die toekoms betref sorgeloos, en in baie opsigte lui, en ondernemingloos voortgesukkel. Hoe armoediger en armsaliger die bestaan van die persoon, hoe vromer is hy.

Ons bely dat ons deur die ewige besluite van God nie belet word om onder sy wil vir onsself te sorg en ons sake te reël nie. God het aan ons die sorg vir ons lewe toevertrou en ons voorsien van middels om die lewe te beveilig en te laat gedy (Gen. $3: 21$ ). Vandaar die goeie reg van assuransies ens. Mooi vind ons die goddelike en die menslike faktor saam- 
verbind in die woorde: „die hart van die mens dink sy weg uit, maar die HERE rig sy voetstappe" (Spr. 16:9). En in die woorde van Joab aan sy soldate: „wees sterk en laat ons ons sterk hou vir ons volk en vir die stede van onse God. Mag die HERE dan doen wat goed is in sy ö̈" (2 Sam. $10: 12$ ).

Dit geld ook van die gebed. Mense wat hierdie belydenis fatalisties verklaar, moet eindig met 'n biddelose wêreld. Dis hulle ideaal, uitgesproke of onuitgesproke. Hulle beweer en moet ook beweer dat die gebede van die gelowiges verkeerd of oorbodig is. Want daarin vra hulle dat die Here vir dinge sal sorg waarvoor Hy van ewigheid af besluit het om te sorg.

So het ons na die onlangs gehoue dag van verootmoediging gehoor dat die opmerking gemaak is dat dit tog sou gereën het, al het die volk hom nie verootmoedig nie. Dis maar net in ander woorde dieselfde wat die Deïste vir ons al so baie maal gesê het: ,julle moet maar meer werk en wetenskapliker boer, en maar minder biddae hou, dan sal dit met julle beter gaan". So redeneer mense wat God in die hemel toesluit en Hom verlaag tot 'n blote Toeskouer van wat op aarde gebeur. Die aarde het $\mathrm{Hy}$ aan die mens gegee, aan die natuur sy wette. En nou laat God maar alles sy verloop hê, en net af en toe gryp $\mathrm{Hy}$ in as die mens heeltemal vasgeloop het. Dis die mense wat bid as die bomme bars, maar in die jare van vrede na die Here nie vra nie.

Vir ons is dit geen probleem dat God antwoord voordat ons roep nie. Dit doen Hy daeliks. Hy gee ons ons brood en gesondheid en krag om te werk nog voordat ons dit van Hom gevra het. Dis vir ons ook geen probleem dat God op sommige plekke dieselfde dag ook al laat reën het nie. Moet God Hom dan skik na ons voorwaardes en na ons stompsinnigheid as $\mathrm{Hy}$ aan ons bo al sy weldade op duidelike wyse wil toon dat Hy goed is? En het $\mathrm{Hy}$ wat die dag van uitkoms bepaal het, nie ook die dag van verootmoediging bepaal en die mense gelei om die dag te kies nie?

Mense wat so redeneer en dit bevraagteken of daar nou werklik sprake kan wees van gebedsverhoring, staan nie meer op theïstiese standpunt nie. Ons het nie 'n God wat maar net die rol van toeskouer vervul nie, maar ons eer 'n God wat Hom nie onbetuig laat nie, deur goed te doen, van die hemel vir ons reën en vrugbare tye te gee en ons harte met voedsel 
en vrolikheid te vervul (Hand. $14: 17$ ). 'n God wat hemel en aarde vervul (Jer. $23: 24$ ), wie se oë op die regverdiges is en sy ore tot hulle hulpgeroep (Ps. $34: 16,18$ ).

Dis die toppunt van ellende om hierdie leerstuk nie te ken nie, dit te verwater of te verdraai, want dan is ons ondankbaar in voorspoedtye, materialisties en aan sinlike genietinge oorgegee, ver van God verwyder wat die lewe is. Ons is ongeduldig of paniekbevange as dit teëloop of as die skaduwees op ons lewenspad val. En wat die toekoms betref, sit ons op moedverloor se vlakte, ook as die lug nog helder is en die son vrolik skyn.

Ten slotte merk ons op dat ons by alles wat gesê is op die grens van die ,wonder" verkeer het. Laat die natuurwette nog opening vir die wonder? En wat is die verhouding tussen natuurwet en wonder? Wonder beteken tog nie dat God in die gewone loop van die natuur ingryp deur 'n natuurwet te verbreek nie. Dis die deterministiese opvatting, wat leer dat in die heelal alles sonder Gods bemoeienis voortbeweeg en dat God net nou en dan ingryp by wyse van 'n wonder. So 'n voorstelling is God onwaardig. Die Here gee geen deeltjie van sy skepping ooit uit sy hand nie, maar hou sy almagtige hand van oomblik tot oomblik daaronder en daarin.

Hoe moet ons dan die verhouding sien van natuurwet tot wonder? Miskien só dat God verborge kragte aan die werk stel wat deur ons menslike verstand nié te rym is met die wette wat Hy vir die natuur daargestel het en waarmee ons bekend is nie. Prof. K. Dijk stel dit só voor dat in die wonders telkens 'n besondere krag van God optree wat die kosmiese wet wat $\mathrm{Hy}$ gegee het nie verbreek of ophef nie, maar alleen 'n tydelike afwyking is van die reëlmatige gang van sake waaraan ons gewoond is.

Ons moet dus teen twee uiterstes waak. Die een is dié van die deterministe, $\mathrm{nl}$. dat in die natuur vaste wette gegee is en God staan daarbuite. Die ander een is dit dat nou uit reaksie teen die naturalisme geen natuurwette aanvaar word nie. God gryp op supranaturalistiese wyse voortdurend in die skepping in. Altwee opvattings beteken die dood vir die religie. So 'n God kan ons nie aanbid nie. Die regte standpunt is seker dat ons die natuurwette nie moet beskou as 'n geslote sisteem wat onder alle omstandighede deterministies op 
die natuur van toepassing is nie. Die ordeninge van God vir sy skepping is altyd aktuele ordeninge van die lewende God wat van oomblik tot oomblik sy skepping daarmee onderhou. Hulle is natuurwette wat deur God verordineer is, maar hulle word van oomblik tot oomblik deur God bestendig. Hulle is in 'n sekere sin "oop" na die kant van God en word deur Hom in diens van sy koninkryk gebruik. Daarom vlug die gelowige nie in ' $n$ irrasionalistiese indeterminisme nie (toeval, sinloosheid, die chaotiese), maar hy probeer om die skeppingsboek van God te lees en hy lees daarin van Gods seën en oordeel, van die gewone en wonderlike dinge.

A. Duvenage.

\section{BOEKBESPREKING}

Leroy Edwin Froom: The conditionalist faith of our fathers, Vol. II. Review and Herald Publishing Co.; Washington, D.C. 1965.

Dis 'n dik en goed gedokumenteerde werk van 1276 paginas. Die bibliografie alleen beslaan 30 bladsye. Dis uitgegee in opdrag van die Sewendedagadventiste. Vol. I, wat ek nie tot my beskikking het nie, handel oor die idee van die onsterflikheid van die siel, van 900 v.C. tot 600 n.C. En hierdie volume dek dan van 600 tot 1963 n.C. Dis meer 'n historiese studie as eksegeties-dogmaties, alhoewel daardie aspekte nie verwaarloos word nie.

Alhoewel ons saam met Froom aanvaar dat die mens nie van nature onsterflik is nie, omdat God alleen onsterflikheid besit, kan ons ons tog ook aan die ander kant nie versoen met die gedagte dat daar nie so iets is as 'n salige of rampsalige "tussentoestand" na die dood nie, maar moet ons saam met Calvyn die idee verwerp van die "sieleslaap" of dat die afgestorwene alleen met die liggaamlike opstanding sal herlewe.

Die boek is die moeite werd om te lees, veral ook die laaste gedeelte waarin die skrywer hom afset teen die Spiritualisme met sy sg. kontakte met die dodewêreld, wat volgens Froom of op bedrog of op demoniese werkinge berus. Hy gee ons veel om oor na te dink.

(Prof.) S. J. van der Walt. 